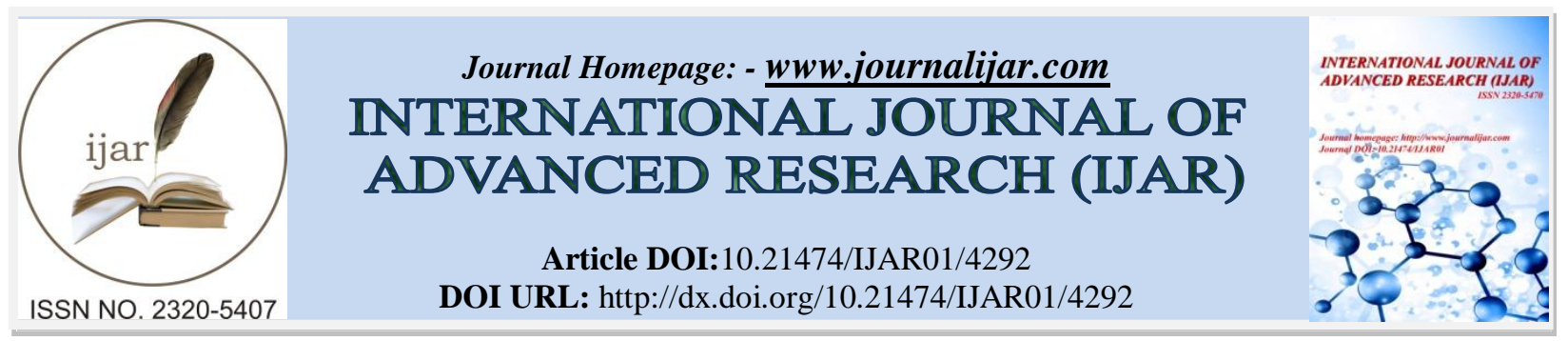

RESEARCH ARTICLE

\title{
DERIVATIVE SPECTROPHOTOMETRIC DETERMINATION OF SOME RARE EARTH ELEMENTS
} IN EGYPTIAN MONAZITE.

\author{
Abd El-Rehim S.S ${ }^{1}$, Mohammed A.A ${ }^{2}$, El-Wakil A.F ${ }^{2}$ and Abd Al AzizR.S ${ }^{2}$. \\ 1. Faculty of Science, Ain Shams University, Cairo, Egypt. \\ 2. Nuclear Materials Authority, P.O. Box 530 El-Maadi, Cairo, Egypt.
}

\section{Manuscript Info}

..........................

Manuscript History

Received: 26 March 2017

Final Accepted: 27 April 2017

Published: May 2017

Key words:-

derivative, determination, rare earth elements.

\section{Abstract}

A sensitive and selective derivative spectrophotometric method is described for the determination of Samarium, Europium and Gadolinium with chrome azurol S and cetylpyridinium chloride (as a cationic surfactant) in concentrate rare earth oxide prepared from Egyptian monazite upgraded to about $97 \%$ mineralogical grade. It was obtained from black sands deposited at Rosetta area on Mediterranean coast. Monazite is resulted as a byproduct during the recovery of the economic heavy minerals. The mineral monazite is composed of rare earth phosphatesalong with thorium and uranium. It contains $55-60 \%$ rare earth oxides. The calibration curve is linear between 0.5 and $12 \mu \mathrm{g} \mathrm{ml}^{-1}$ metal. The influence of various parameters and reaction conditions for maximum colour development was investigated. The standard deviations for determination are 0.208 , 0.208 and 0.305, percentage errors 3.5, 4.9 and $5.1 \%$, for Samarium, Europium and Gadolinium respectively. The recommended method showed good sensitivity and selectivity.

Copy Right, IJAR, 2017,. All rights reserved.

\section{Introduction:-}

Rare earth elements are a group of chemical elements that occur together in the periodic table. The rare earth elements are all metals, and the group is often referred to as the "rare earth metals." These metals have many similar properties and that often causes them to be found together in geologic deposits. They are also referred to as "rare earth oxides" because many of them are typically sold as oxide compounds (Belli, 2007).

Rare earth metals and alloys that contain them are used in many devices that people use every day such as computer memory, DVDs, rechargeable batteries, cell phones, catalytic converters, magnets, fluorescent lighting and much more, as catalysts, phosphors, and polishing compounds (Spedding F. and Daane AH., 1961).These are used for air pollution control, illuminated screens on electronic devices, and the polishing of optical-quality glass (United States Geological Survey, 2014). 


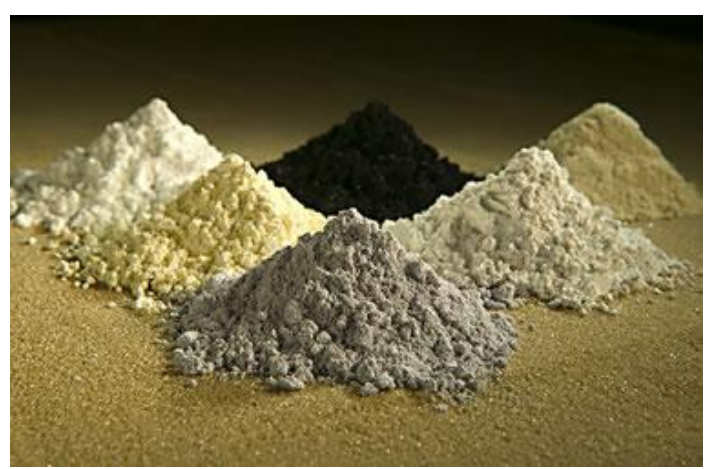

Clockwise from top center: praseodymium, cerium, lanthanum, neodymium, samarium, and gadolinium. Image by Peggy Greb, USDA image gallery.

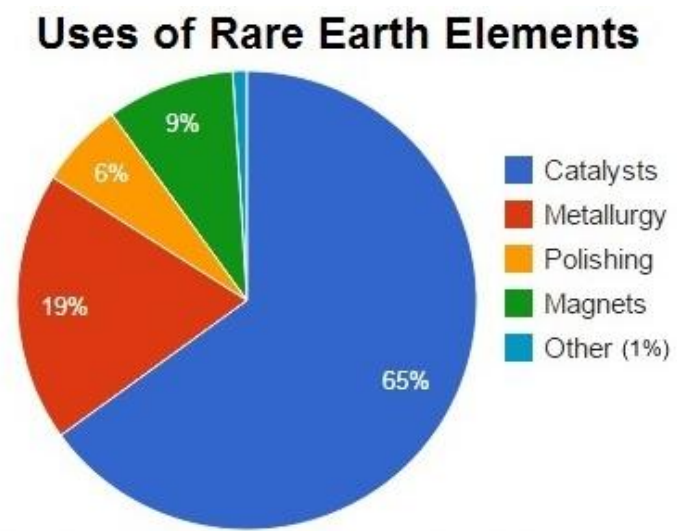

Uses in the United States as reported by the United States Geological Survey Mineral Commodity Summary, 2013

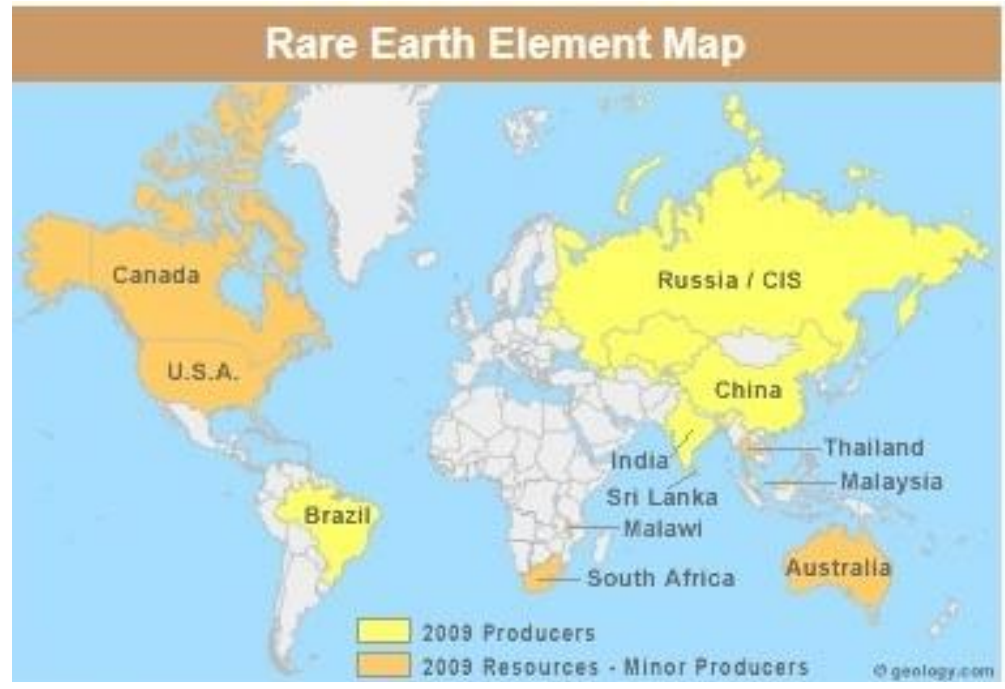

Rare earths are essential for many military uses, including: missile guidance systems, lasers, and smart bombs; sonar and underwater mine detection; radar and antimissile defense; jet engines; laser range finders and targeting; electronic countermeasures; and satellite communication systems (Humphries M., 2013).

Different methods have been used for the determination of Samarium, Europium and Gadolinium. A procedure for the simultaneous determination of dysprosium, europium, samarium and terbium by laser-induced derivative 
fluorimetry is based on used the first-derivative and Kalman-filter techniques. The procedure is satisfactory for the simultaneous determination of these four lanthanides (Jianjun L., et al., 1990).

A sensitive simple method for the determination of trace amounts of samarium by spectrophotometry is based on the formation of the samarium-chrome azurol S (CAS)-cetylpyridinium chloride (CPC) complex in micellar medium (Marezenko M., 1986, Nishida H., 1991 and Sahin U., et al., 1997). Beer's law is obeyed from 0.05-2 mg $\mathrm{l}^{-1}$ of samarium at $505 \mathrm{~nm}$ as Sm-CAS-CPC complex. Optimal conditions for the samarium determination were studied (Soylak M. and Türkoğlu O., 2000).

The used concentrate rare earth oxide has been extracted from Egyptian monazite upgraded to about $97 \%$ mineralogical grade. It was obtained from black sands deposited at Rosetta area on Mediterranean coast. Monazite is resulted as a byproduct during the recovery of the economic heavy minerals. The mineral monazite is composed of rare earth phosphatesalong with thorium and uranium(Nishida H., 1991, SoylakM.,et.al, 1997).

In the present work, the ability to simultaneous determine Samarium, Europium and Gadolinium in the produced concentrate rare earth oxide using chrome azurol S (CAS) dye and cetylpyridinium chloride (CPC) as cationic surfactant was studied. Optimum factors affecting the formation and measuring of the complexes such as maximum wavelength, $\mathrm{pH}$, initial concentration of dye and surfactant, molar ratios and calibration curves were investigated.

\section{Experimental:-}

Instrumentation:-

A double beam UV-Visible spectrophotometer model Shimadzu (UV-11601) from Japan was used, The spectrophotometer ranges from 190 to $1100 \mathrm{~nm}$, with a resolution of $2 \mathrm{~nm}$ and a wavelength accuracy of $\pm 0.5 \mathrm{~nm}$ were conducted.

A NEL $980 \mathrm{pH}$ meter was used for recording the $\mathrm{pH}$ of the studied solutions. This was calibrated with three successive buffer solutions (4, 7 and 10).

\section{Reagents:-}

The chemicals and reagents used through the experiments carried out in the present study were analytical grade. Doubly distilled water was used for preparing all solutions.

Sodium hydroxide, Ammonium hydroxide, Sodium tetraborate, Hydrochloric acid, Sulphoric acid, Nitric acid,Perchloric acid,Cetylpyridinium chloride (Sigma-Aldrich), Dowex50W-X8 (Acros-Organic), EDTA (Merck), Chrome azurol S, Standard solutions $1000 \mathrm{ppm} \mathrm{Sm}$, Eu and Gd (Fluka). A solution of $10^{-3} \mathrm{M}$ of dye solution was prepared by dissolving $0.2 \mathrm{~g}$ of Chrome azurol S (CAS) dye with double distilled water in a 100 ml volumetric flask and completed to the mark to give a concentration of $0.2 \%$. Cetylpyridinium chloride (CPC) solution $10^{-3} \mathrm{M}$ was prepared by dissolving $0.2 \mathrm{~g}$ of cetylpyridinium chloride in doubly distilled water in $100 \mathrm{ml}$ volumetric flask and completed to the mark to give a concentration of $0.2 \%$. Buffer solution was prepared by dissolving $0.4 \mathrm{~g}$ of sodium hydroxide and $1.0061 \mathrm{~g}$ of sodium tetraborate in double distilled water in $100 \mathrm{ml}$ volumetric flask and completed to the mark to obtain buffer solution of $0.1 \mathrm{M}$ sodium hydroxide and $0.05 \mathrm{M}$ sodium tetraborate.

\section{Results and Discussions:-}

\section{Spectrum of chrome azurol $S$ dye and complexes:-}

Absorption spectrum of chrome azurol S dye could be defined when measured against water as a blank. Figure (1) represents the absorption spectrum of chrome azurol S dye as well as the absorption spectra of Sm, Eu and Gd-CASCPS complexes against water as a blank in the visible regios between $250 \mathrm{~nm}-650 \mathrm{~nm}$. Inspection of the data reveal that the maximum absorbance value for the dye is at $450 \mathrm{~nm}$ while for the three complexes is at $350 \mathrm{~nm}$. 


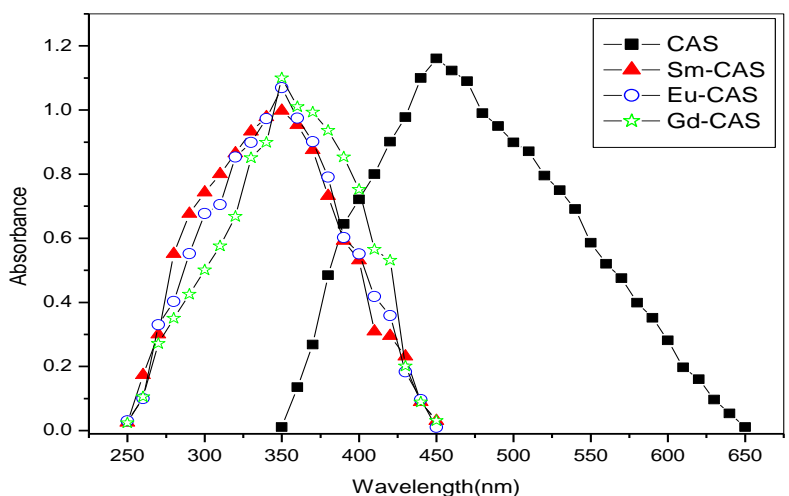

Fig 1:- Absorption spectra of CAS-CPC blank against water, Sm, Eu and Gd-CAS-CPC complexes against reagent blank.

Selection of the type of derivative for the spectrophotometric determination of the complexes:-

Derivatisation of spectra is the simplest method for increasing the selectivity, this operation allows to overcome spectral interferences and as a consequence leads to increase the selectivity of assay. Derivatisation of digital data is well known method of separation useful signals from noised data, and by tested first, second, third and fourth derivative it is found that, the selectivity increased by fourth derivative.

Selection of the suitable $\mathrm{pH}$ for the spectrophotometric determination of the complexes:-

It is found necessary to study the effect of the $\mathrm{pH}$ values on the formation of the complexes. Most colored metallochrome reagents are $\mathrm{pH}$ indicators ( $\mathrm{pH}$ dependence reagents) where they change colour normally in complexation with metals but also due to their indicator properties. Thus the $\mathrm{pH}$ value plays an important role in the colour intensity of the dye itself and the formed complex. Firstly the effect of different $\mathrm{pH}$ values on the absorption spectrum of free chrome azurol $\mathrm{S}$ dye will be studied. For this reason the basicity of the aqueous solution was changed for different $\mathrm{pH}$ values ranging from 6.5 to 8 (Soylak M. and Türkoglu O, 2000) and the dye concentration was kept constant in all solutions where the final volume of these solutions was completed to $25 \mathrm{ml}$. It is clearly evident that the maximum absorption occurs at $\mathrm{pH} 7.5$ which adjusted by borax buffer. Table (1) summarized the effect of changing $\mathrm{pH}$ on the absorbance of complexes.

Table 1:- Effect of buffer $(\mathrm{pH})$ on the absorbance of $\mathrm{Sm}, \mathrm{Eu}$ and $\mathrm{Gd}$ complexes.

\begin{tabular}{|c|c|c|c|}
\hline $\mathrm{pH}$ & Absorbance of $(\mathrm{Sm})$ & Absorbance of $(\mathrm{Eu})$ & Absorbance of $(\mathrm{Gd})$ \\
\hline 6.5 & 0.05 & 0.059 & 0.05 \\
\hline 7 & 0.043 & 0.036 & 0.046 \\
\hline $\mathbf{7 . 5}$ & $\mathbf{0 . 0 5 2}$ & $\mathbf{0 . 0 7 3}$ & $\mathbf{0 . 0 8 1}$ \\
\hline 8 & 0.04 & 0.041 & 0.059 \\
\hline
\end{tabular}

Effect of surfactant concentration on the absorbance of the complexes:-

It was necessary to optimize the concentration of CPC as a cationic surfactant, studying the effect of its concentration on the sensitivity and molar absorbitivity of the produced complexes. For this purpose different volumes of $\left(10^{-3} \mathrm{M} \mathrm{CPC}\right)$ solution were added to a series of $25 \mathrm{ml}$ volumetric flasks containing fixed volumes of (10 ${ }^{3} \mathrm{M}$ dye) and (Sm, Eu or $\mathrm{Gd}$ ) and adjust to $\mathrm{pH} 7.5$ by borax buffer. The final volumes of these solutions were completed with doubly distilled water. The absorbance of each solution was then measured against blank. Figure (2) shows that, maximum absorbance was attained at $0.5 \times 10^{-3} \mathrm{M}$ of $(\mathrm{CPC})$ for the three metals. 


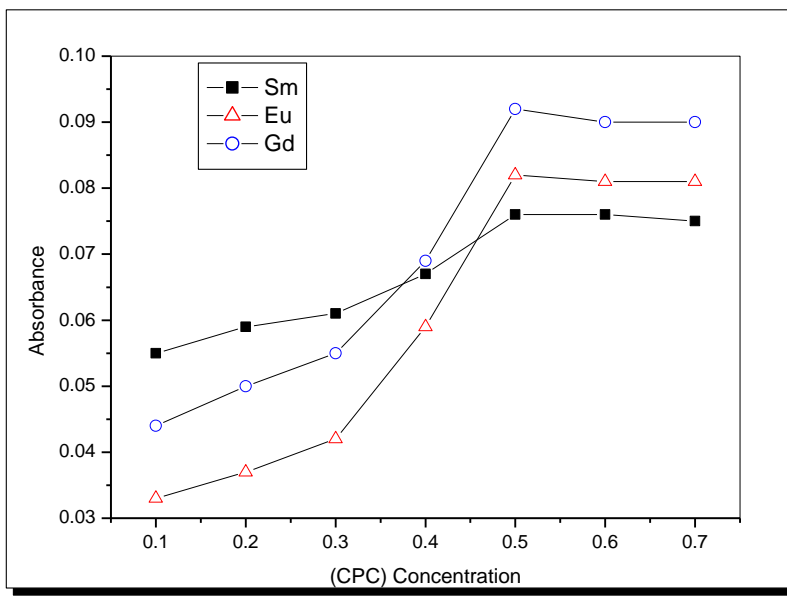

Fig 2:-. Effect of surfactant concentration on the absorbance of complexes.

Effect of chrome azurol $S$ dye concentration on the absorbance of the complexes:-

The chrome azurol $\mathrm{S}$ dye concentration should be optimized since an amount; which is lesser or higher than necessary, would cause deviation from Beer's law in the construction of calibration curve. For this purpose, different volumes of $10^{-3} \mathrm{M}$ chrome azurol S dye were added to a series of volumetric flasks of $25 \mathrm{ml}$ volume containing $1 \mathrm{ml}$ of $10^{-3} \mathrm{M}$ (Sm, Eu, Gd) and $0.5 \mathrm{ml}$ of $10^{-3} \mathrm{M}$ of CPC where at adjusted $\mathrm{pH} 7.5$. The volume was completed to $25 \mathrm{ml}$ and the absorbance of each solution was then measured. Figure (3) shows that, the maximum absorbance of the complexes occur at a concentration of $1 \times 10^{-3} \mathrm{M}$ of chrome azurol $\mathrm{S}$ dye.

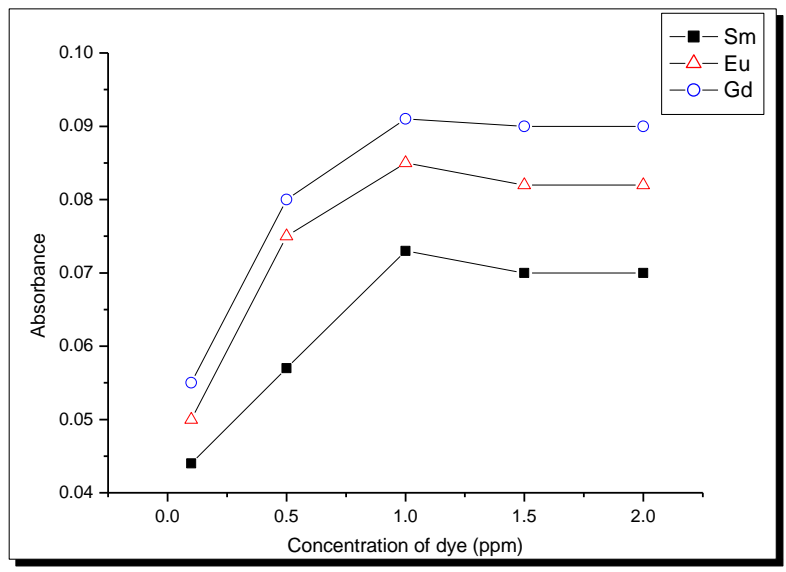

Fig 3:-. Effect of chrome azurol S concentration on the absorbance of the complexes.

Effect of duration time on the stability of the complexes:-

The (M-CAS-CPC) complexes were left for period of time. Their absorbance were measured periodically each 10 minutes for the first half hour, then left to another half hour and then measured again. (Table 2) indicates that, the best absorbance of the complexes were between 10 minutes and 30 minutes.

Table 2:- Effect of duration time on the stability of the complexes.

\begin{tabular}{|c|c|c|c|}
\hline Time (min) & $\begin{array}{c}\text { Absorbance } \\
\text { of Sm }\end{array}$ & $\begin{array}{c}\text { Absorbance } \\
\text { of Eu }\end{array}$ & $\begin{array}{c}\text { Absorbance } \\
\text { of Gd }\end{array}$ \\
\hline Zero & 0.053 & 0.055 & 0.035 \\
\hline 10 & 0.073 & 0.085 & 0.095 \\
\hline 20 & 0.073 & 0.085 & 0.094 \\
\hline 30 & 0.072 & 0.085 & 0.094 \\
\hline 60 & 0.056 & 0.059 & 0.040 \\
\hline
\end{tabular}




\section{Composition of the complex:-}

In the present work, continuous variation method was used to investigate the ratios between dye and metal. In continuous variation method the molarities of both components (metal-CAS) were changed while keeping the total number of moles of both components constant while surfactant and buffer solutions unvaried. Figures (4, 5 and 6$)$ indicate that, the molar ratio of the complexes Sm, Eu and Gd-CAS is 1:1.

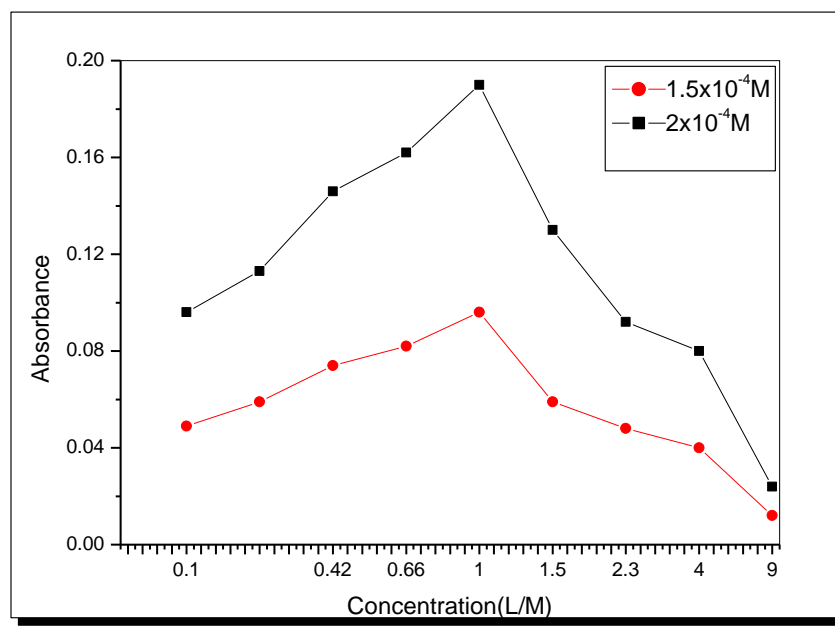

Fig 4:- Continuous variation method for estimating the molar ratio between Sm and CAS complex.

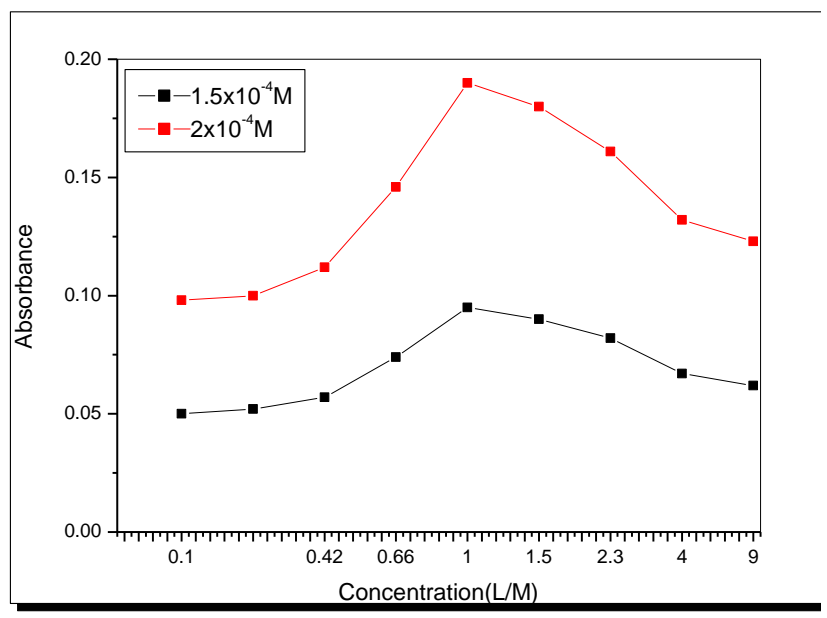

Fig 5:-Continuous variation method for estimating the molar ratio between Eu and CAS complex. 


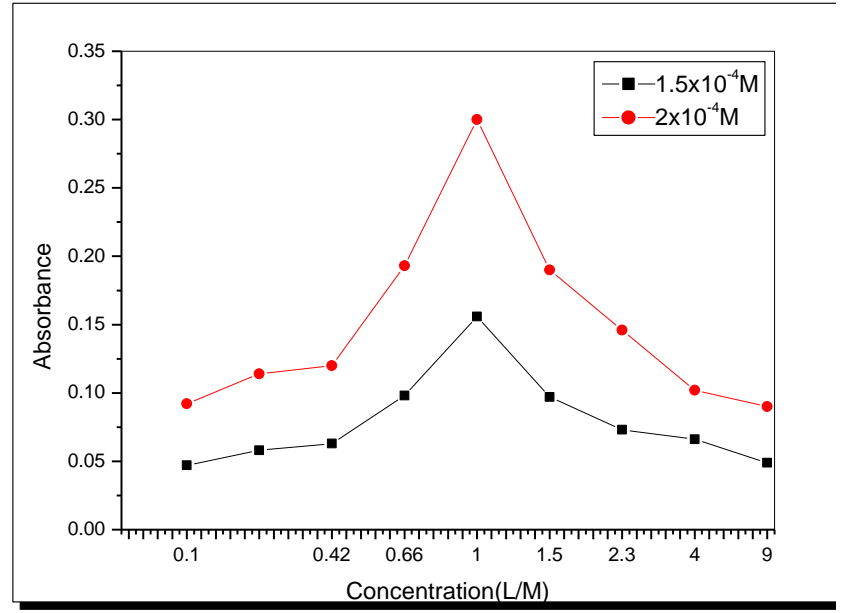

Fig 6:- Continuous variation method for estimating the molar ratio between Gd and CAS complex.

\section{Construction Of Calibration Curves:-}

After the detailed study of the relevant factors affecting the chrome azurol S spectrophotometric determination of Samarium, Europium and Gadolinium, it was found necessary to determine the concentration ranges of Samarium, Europium and Gadolinium above and below which no further complexes could be formed and hence determined.

These two limits could be identified through the construction of calibration curves for the complexes. This spectrophotometric determination must be carried out within the concentration range which Beer's law is obeyed.

The fourth derivative spectra provide linear calibration graphs in the range from 0.3 to $12 \mu \mathrm{g} \mathrm{ml}^{-1}$ for $\mathrm{Sm}, \mathrm{Eu}$ and $\mathrm{Gd}$ respectively as shown in Figures (7, 8 and 9).

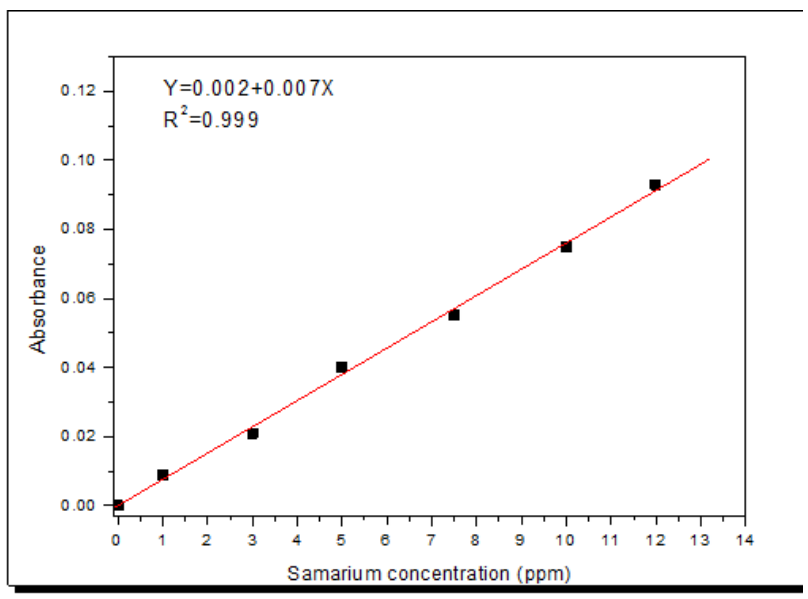

Fig 7:- Calibration curve using $4^{\text {th }}$. Order spectrophotometric determination of Samarium. 


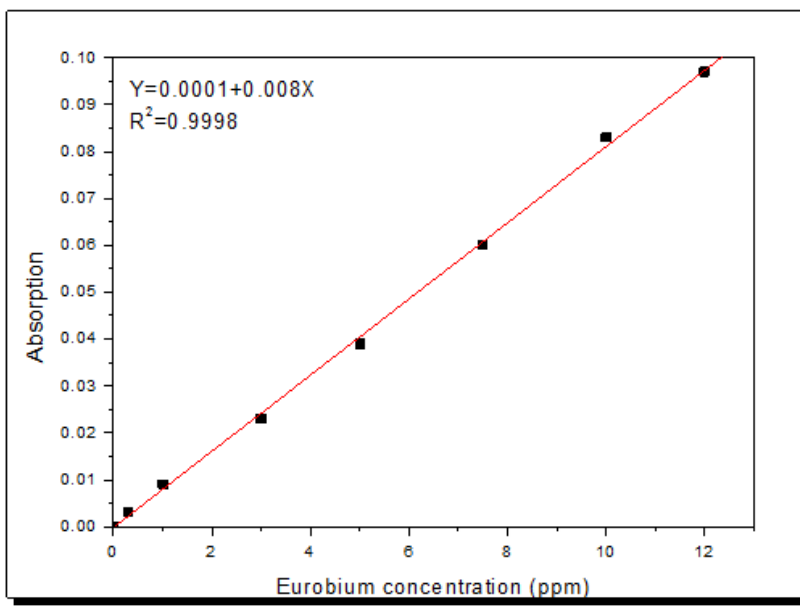

Fig 8:- Calibration curve using $4^{\text {th }}$. Order spectrophotometric determination of Europium.

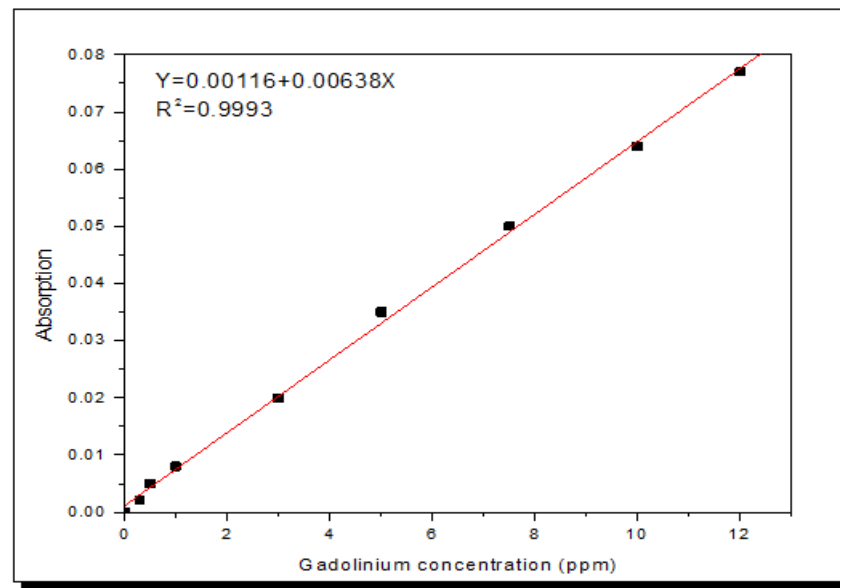

Fig 9:-Calibration curve using $4^{\text {th }}$. Order spectrophotometric determination of Gadolinium.

\section{Studies the interference Effect:-}

It was necessary to study the interference effect of the elements under studying ( $\mathrm{Sm}, \mathrm{Eu}$ and $\mathrm{Gd}$ ) on each other, and some other rare earth elements associated with them.

Table 3:- Interference effect of Eu concentration on the determination of Sm-CAS-CPC complex.

\begin{tabular}{|c|c|}
\hline Conc. of Eu $(\mathrm{ppm})$ & Absorbance of Sm \\
\hline 0 & 0.391 \\
\hline 0.001 & 0.391 \\
\hline 0.003 & 0.390 \\
\hline 0.005 & 0.391 \\
\hline 0.007 & 0.390 \\
\hline 0.015 & 0.501 \\
\hline 0.025 & 0.553 \\
\hline 0.050 & 0.600 \\
\hline
\end{tabular}

Table 4:- Interference effect of Gd concentration on the determination of Sm-CAS-CPC complex.

\begin{tabular}{|c|c|}
\hline Conc. of Gd (ppm) & Absorbance of Sm \\
\hline 0 & 0.391 \\
\hline 0.001 & 0.391 \\
\hline 0.003 & 0.390 \\
\hline 0.005 & 0.391 \\
\hline
\end{tabular}




\begin{tabular}{|l|l|}
\hline 0.007 & 0.390 \\
\hline 0.015 & 0.601 \\
\hline 0.025 & 0.653 \\
\hline 0.050 & 0.703 \\
\hline
\end{tabular}

Table 5:- Interference effect of Gd concentration on the determination of Eu-CAS-CPC complex.

\begin{tabular}{|c|c|}
\hline Conc. of Gd $(\mathrm{ppm})$ & Absorbance of Eu \\
\hline 0 & 0.299 \\
\hline 0.001 & 0.299 \\
\hline 0.003 & 0.297 \\
\hline 0.005 & 0.297 \\
\hline 0.007 & 0.299 \\
\hline 0.015 & 0.541 \\
\hline 0.025 & 0.653 \\
\hline 0.050 & 0.703 \\
\hline
\end{tabular}

From studying the interference effect (Tables 3, 4 and 5), it was shown clearly that conventional spectrophotometry method is inapplicable for determination of Sm, Eu and $\mathrm{Gd}$ in presence of each other. It was found that fourth order derivative is the suitable one for the determination of $\mathrm{Sm}, \mathrm{Eu}$ and $\mathrm{Gd}$ in presence of each other.

According to the composition of the concentrates of the investigated samples, the effect of interfering lanthanide elements $\mathrm{La}, \mathrm{Pr}, \mathrm{Nd}$ and Y upon determination of Sm, Eu and Gd with CAS and CPC were studied. For this purpose, a series of concentrations for mixture of $\mathrm{Sm}$, Eu and $\mathrm{Gd}$ were prepared and series of concentrations for each interfering element with a constant concentration of Sm, Eu and $\mathrm{Gd}\left(1 \mu \mathrm{g} \mathrm{ml}^{-1}\right)$ were prepared. For a second series, standard solution of Sm, Eu and Gd only (without LREEs) was measured at the optimized conditions against reagent blank at $\lambda_{\max } 350 \mathrm{~nm}$, then each prepared solution of Sm, Eu and Gd with the LREEs (at different concentrations) were measured at the same optimized conditions. Tables (6, 7, 8 and 9) indicate that the concentration of $\mathrm{La}, \mathrm{Nd}, \mathrm{Pr}$ and $\mathrm{Y}$ thatmixed with $\mathrm{Sm}, \mathrm{Eu}$ and Gd should not exceed than 0.007, 0.06 and $0.008 \mu \mathrm{g} \mathrm{ml}^{-1}$ respectively. The excess above these concentrations cause systematic error on determination of $\mathrm{Sm}$, $\mathrm{Eu}$ and $\mathrm{Gd}$ using conventional spectrophotometry.

Table 6:- Interference effect of La concentration on the determination of Sm, Eu and Gd-CAS-CPC complex.

\begin{tabular}{|c|c|}
\hline Conc. of La $(\mathrm{ppm})$ & Absorbance \\
\hline 0 & 0.990 \\
\hline 0.001 & 0.980 \\
\hline 0.002 & 0.980 \\
\hline 0.003 & 0.990 \\
\hline 0.007 & 0.995 \\
\hline 0.009 & 0.950 \\
\hline 0.013 & 0.970 \\
\hline 0.027 & 1.540 \\
\hline 0.041 & 1.950 \\
\hline
\end{tabular}

Table 7:- Interference effect of $\mathrm{Nd}$ concentration on the determination ofSm, Eu and Gd-CAS-CPC complex.

\begin{tabular}{|c|c|}
\hline Conc. of Nd (ppm) & Absorbance \\
\hline 0 & 0.990 \\
\hline 0.01 & 0.990 \\
\hline 0.02 & 0.980 \\
\hline 0.03 & 0.993 \\
\hline 0.06 & 0.993 \\
\hline 0.1 & 1.530 \\
\hline 0.13 & 1.540 \\
\hline 0.27 & 1.920 \\
\hline 0.41 & 1.960 \\
\hline
\end{tabular}


Table 8:- Interference effect of $\operatorname{Pr}$ concentration on the determination of Sm, Eu and Gd-CAS-CPC complex.

\begin{tabular}{|c|c|}
\hline Conc. of $\operatorname{Pr}(\mathrm{ppm})$ & Absorbance \\
\hline 0 & 0.990 \\
\hline 0.001 & 0.990 \\
\hline 0.002 & 0.990 \\
\hline 0.004 & 0.990 \\
\hline 0.005 & 0.990 \\
\hline 0.007 & 0.990 \\
\hline 0.008 & 0.990 \\
\hline 0.014 & 1.797 \\
\hline 0.028 & 1.820 \\
\hline
\end{tabular}

Table 9:- Interference effect of Y concentration on the determination of Sm, Eu and Gd-CAS-CPC complex.

\begin{tabular}{|c|c|}
\hline Conc. of $\mathrm{Y}(\mathrm{ppm})$ & Absorbance \\
\hline 0 & 0.990 \\
\hline 0.0008 & 0.990 \\
\hline 0.0018 & 0.990 \\
\hline 0.0027 & 0.990 \\
\hline 0.0035 & 0.990 \\
\hline
\end{tabular}

Accordingly, it was found necessary to apply derivative spectrophotometry technique to overcome the effect of interfering elements on measuring Sm, Eu and $\mathrm{Gd}$ in the REE concentrate. It was found that fourth order derivative is the suitable one for the determination of Sm, Eu and Gd-CAS-CPC complex in presence of Pr and $\mathrm{Nd}$ and in the presence of each other but it's necessary to eliminate La element firstly. To eliminate La element about 15g of the pure concentrate rare earth oxides was dissolved in the minimum amount of concentrated $\mathrm{HCl}$ and the obtained solution was completed up to $500 \mathrm{ml}$ by distilled water after $\mathrm{pH}$ adjustment to 2.5 (total REO concentrate about 30 $\mathrm{g} / \mathrm{l}$ ). About $450 \mathrm{ml}$ of the latter was used to saturate an adsorption resin bed (Dowex 50W-X8,100-200 mesh size) in its hydrogen form packed in a small column $(2.2 \mathrm{~cm}$ height and $1.1 \mathrm{~cm}$ diameter). This was followed by washing the resin bed with distilled water until chloride-free. The La load was then selectively eluted using the normal elution procedure, the normal elution procedure $(1 \mathrm{ml} / \mathrm{min})$ was performed with a known volume of $0.015 \mathrm{M}$ EDTA solution.

The effects of anions $\left(\mathrm{Cl}^{-}, \mathrm{NO}^{-3}, \mathrm{SO}_{4}{ }^{-2}\right.$ and $\left.\mathrm{ClO}^{-4}\right)$ on measuring of $\mathrm{Nd}$ with $\mathrm{CAS}$ and $\mathrm{CPC}$ at the optimized conditions were studied. For this purpose a series of standard solutions of the studied anions (from $0.1 \times 10^{-4} \mathrm{M}$ to $\left.2 \times 10^{-2} \mathrm{M}\right)$ were prepared, then mix $1 \mathrm{ml}$ of each standard solution with $1 \mathrm{ml}$ of $\left(10^{-3} \mathrm{M}\right)$ of each $\mathrm{Sm}$, Eu and $\mathrm{Gd}, 1 \mathrm{ml}$ of $\left(10^{-3} \mathrm{M}\right)$ CAS and $0.5 \mathrm{ml}$ of $\left(10^{-3} \mathrm{M}\right) \mathrm{CPC}$, at $\mathrm{pH} 7.5$, then up to volume in $25 \mathrm{ml}$ volumetric flask. The standard solution of each matals in the absence and presence of various concentrations of the anions were measured at the optimized conditions against reagent blank. The critical concentration of each anion used above which interference began to disturb the absorbance of pure metal-CAS-CPC complex was determined. Table (10) reveals that the measuring of metals in presence of $\mathrm{Cl}^{-}, \mathrm{NO}^{-3}, \mathrm{SO}_{4}^{-2}$ and $\mathrm{ClO}^{-4}$ be possible conventionally up to $2,1 \times 10^{-2}, 0.9 \times 10^{-2}$ and $0.7 \times 10^{-2} \mathrm{M}$ respectively, the excess above these concentrations cause systematic error upon determination.

Table 10: Interference effect of anions concentration on the determination of M-CAS-CPC complex.

\begin{tabular}{|c|c|c|c|c|}
\hline $\begin{array}{c}\text { Conc. of anions } \times 10^{-2} \\
\mathrm{M}\end{array}$ & $\begin{array}{c}\text { Absorbance } \\
\text { Of } \mathrm{Cl}^{-}\end{array}$ & $\begin{array}{c}\text { Absorbance } \\
\text { Of NO }\end{array}$ & $\begin{array}{c}\text { Absorbance } \\
\text { Of } \mathrm{SO}_{4}^{-2}\end{array}$ & $\begin{array}{l}\text { Absorbance } \\
\text { Of } \mathrm{ClO}^{-4}\end{array}$ \\
\hline 0 & 0.991 & 0.989 & 0.990 & 0.990 \\
\hline 0.1 & 0.990 & 0.990 & 0.990 & 0.991 \\
\hline 0.3 & 0.990 & 0.991 & 0.992 & 0.990 \\
\hline 0.5 & 0.990 & 0.990 & 0.992 & 0.990 \\
\hline 0.7 & 0.989 & 0.991 & 0.990 & 0.895 \\
\hline 0.9 & 0.990 & 0.990 & 0.795 & 0.890 \\
\hline 1 & 0.991 & 0.799 & 0.775 & 0.831 \\
\hline 2 & 0.851 & 0.613 & 0.710 & 0.758 \\
\hline 3 & 0.697 & 0.435 & 0.597 & 0.701 \\
\hline
\end{tabular}


From studying the interference effect of these anions, it was shown clearly that conventional spectrophotometry method is inapplicable for determination in presence of other elements due to the interference effect, but use fourth order derivative to overcome the interference.

\section{Application:-}

The Egyptian monazite is mostly derived from granite and pegmatite (Hammoud, 1966). Placer monazite is the most important source of rare earth elements, it has been largely abandon because of its high thorium content. (ElHinnawi, 1964 and Dabbour, 1994) revealed that, this monazite contains 5.92 to $6.04 \% \mathrm{ThO}_{2}, 0.45$ and $0.48 \%$ $\mathrm{U}_{3} \mathrm{O}_{8}$ and 70.7. and $61.31 \mathrm{wt} \% \mathrm{RE}_{2} \mathrm{O}_{3}$. Therefore processing of monazite is of great importance as a source of rare earth elements and thorium - uranium concentrates production.

To test the utility of the method, use concentrate rare earth oxide extracted from Egyptian monazite upgraded to about $97 \%$ mineralogical grade. The oxide was obtained from black sands deposited at Rosetta area on Mediterranean coast. Monazite is resulted as a byproduct during the recovery of the economic heavy minerals. The standard deviations are 0.208, 0.208 and 0.305 and errors are $3.5 \%, 4.9 \%$ and $5.1 \%$ for Sm, Eu and Gd respectively. Table (11) shows the results from the present method and compared with ICP-OES (Nuclear Material Authority).

Table 11:- Analytical results of Sm, Eu and Gd (ppm) in sample by the present developed method in comparison to ICP-OES

\begin{tabular}{|c|c|c|c|}
\hline Element & $\begin{array}{c}\text { The present developed } \\
\text { method }\end{array}$ & ICP-OES method & Error \% \\
\hline $\mathrm{Sm}$ & 9.2 & 8.9 & 3.5 \\
\hline $\mathrm{Eu}$ & 6.5 & 6.2 & 4.9 \\
\hline $\mathrm{Gd}$ & 4.3 & 4.5 & 5.1 \\
\hline
\end{tabular}

\section{Statistical Evaluation Of The Results:-}

Statistical analysis by using appropriate statistical parameters is here in attempted to cast some light on the significance of the results.

\section{Standard error:-}

Calculation of standard error is very important in the field of applied analytical chemistry. It is used for determination of error percentage for any developed method according to the following successive equations:

Standard deviation $(\mathrm{S})=\left[\left(\sum \mathrm{X}_{1}-\overline{\mathrm{X}}\right)^{2} / \mathrm{N}-1\right]^{1 / 2}$

Standard error (S.E.) $=\mathrm{S} / \mathrm{N}^{1 / 2}$

Error $\%=100($ S.E. $/ \bar{X})$

$\operatorname{RSD} \%=100(\mathrm{~S} / \overline{\mathrm{X}})$

Where:

$\mathrm{X}_{1}$ measurement value.

$\mathrm{X}$ mean of the measurement values .

$\mathrm{N}$ number of samples (number of measurements).

\begin{tabular}{|c|c|c|c|c|c|c|c|}
\hline Element & Content & Mean X & $\mathrm{S}$ & $\mathrm{S}^{2}$ & $\mathrm{SE}$ & Error\% & RSD\% \\
\hline $\mathrm{Sm}$ & 9.2 & 9.133 & 0.208 & 0.043 & 0.320 & 3.5 & 2.279 \\
& 9.3 & & & & & & \\
\hline $\mathrm{Eu}$ & 8.9 & & & & & & \\
& 6.5 & 6.433 & 0.208 & 0.043 & 0.320 & 4.9 & \\
& 6.6 & & & & & & \\
\hline $\mathrm{Gd}$ & 4.3 & 4.23 & 0.305 & 0.093 & 0.218 & 5.1 & 7.216 \\
& 3.9 & & & & & & \\
& 4.5 & & & & & \\
\hline
\end{tabular}

\section{Concolusion:-}

The proposed method involves the use of fourth derivative spectra for the determination of Samarium, Europium and Gadolinium complex with chrome azurol S dye in the presence of cetylpyridinium chloride. The method is 
sensitive and selective in the presence of other rare earths and successfully used for the determination of Samarium, Europium and Gadolinium in concentrate rare earth oxide extracted from Egyptian monazite upgraded to about 97 $\%$ mineralogical grade. Which obtained from black sands deposited at Rosetta area on Mediterranean coast.

\section{References:-}

1. Jianjun L., Yun'e Z. and Guanquan C., Talanta, Volume 37, August 1990, Pages 809-813.

2. Soylak M. and Türkoğlu O., Spectrophotometric determination of samarium (III) with chrome azurol S in the presence of cetylpyridinium chloride. Talanta, Volume 53 (2000), p. 125-129.

3. Humphries M., Specialist in Energy Policy, 2013.

4. United States Geological Survey, Mineral Commodity Summaries, 2014.

5. Hammoud, 1966.

6. Dabbour, 1994.

7. El-Hinnawi, Mineralogical and Geochemical Studies on Egyptian Black Sands. Beitr Mineral Petrol 9:519, 1964.

8. Nishida H. Anal .Sei. (1991) 975.

9. Soylak M., Sahin U., Ulgen A., Elei L. and Dogan M. Anal. Sei, 13 (1997) 287.

10. Spedding F, Daane AH: "The Rare Earths", John Wiley \& Sons, Inc., 1961.

11. Belli, Bernabei R., Cappella F., Cerulli R., Dai C.J., Danevich F.A., d'Angelo A., Incicchitti A., Kobychev V.V, Nagorny S.S, Nisi S., Nozzoli F., Prosperi D., Tretyak V.I. and Yurchenko S.S., "Search for $\alpha$ decay of natural Europium", 2007.

12. Marezenko M. Separation and Spectrophotometric Determination of Elements. Wiley. Chichester, 1986.

13. Nishida H. Anal. Sci. 7 (1991) 975.

14. Sahin U., Soylak M., Ulgen A., Eler L. and Dogan M. Anal. Sci. 13 (1997) 287. 